\title{
Non-isothermal plasticity model for cyclic behaviour of soils
}

\author{
L. Laloui ${ }^{1, *, \dagger}$ and C. Cekerevac ${ }^{2}$ \\ ${ }^{1}$ Ecole Polytechnique Fédérale de Lausanne (EPFL), Soil Mechanics Laboratory, Station 18, \\ CH-1015 Lausanne, Switzerland \\ ${ }^{2}$ Stucky Ltd, Rue du Lac 33, 1020 Renens, Switzerland
}

\begin{abstract}
SUMMARY
On the one hand, it has been observed that liquefaction-induced shear deformation of soils accumulates in a cycle-by-cycle pattern. On the other hand, it is known that heating could induce plastic hardening. This study deals with the constitutive modelling of the effect that heat may have on the cyclic mechanical properties of cohesive soils, a relatively new area of interest in soil mechanics. In this paper, after a presentation of the thermo-mechanical framework, a non-isothermal plasticity cyclic model formulation is presented and discussed. The model calibration is described based on data from laboratory sample tests. It includes numerical simulations of triaxial shear tests at various constant temperatures. Then, the model predictions are compared with experimental results and discussed in the final section. Both drained and undrained loading conditions are considered. The proposed constitutive model shows good ability to capture the characteristic features of behaviour. Copyright (C) 2007 John Wiley \& Sons, Ltd.
\end{abstract}

Received 31 August 2006; Revised 2 April 2007; Accepted 7 April 2007

KEY WORDS: constitutive modelling; elasto-thermoplasticity; cyclic behaviour; thermo-mechanics; numerical simulation; multi-surface plasticity; earthquake

\section{INTRODUCTION}

In recent years, geomechanical problems in non-isothermal conditions have received increasing attention as a result of the demand for new types of applications, such as geothermal foundations $[1,2]$. The geothermal use of concrete geostructures (piles, walls and slabs) is an environmentally friendly way of cooling and heating residential, office and commercial buildings at low additional cost. With such geothermal structures, it is possible to transfer energy from the ground to fluid-filled pipes cast in concrete and then to building environments (Figure 1). The idea behind energetic geostructures is to take advantage of the thermal storage capacity of the ground as an energy storage system by using the foundation of a building. In unrelated applications of thermal technologies

\footnotetext{
*Correspondence to: L. Laloui, Ecole Polytechnique Fédérale de Lausanne (EPFL), Soil Mechanics Laboratory, Station 18, CH-1015 Lausanne, Switzerland.

†E-mail: lyesse.laloui@epfl.ch
}

Copyright (c) 2007 John Wiley \& Sons, Ltd. 


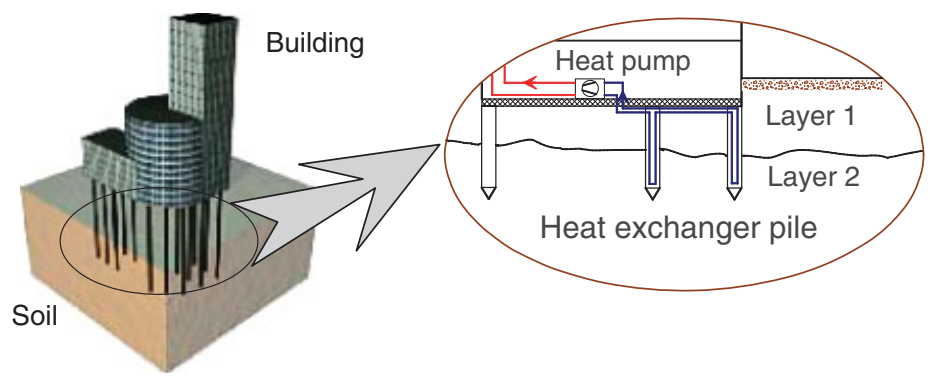

Figure 1. Schematic representation of a heat exchanger pile system.

(off-shore engineering, oil and gas extraction from deep formations, geothermal energy extraction, energy resource transportation, underground nuclear waste disposal, etc.), heating of foundations may also have an important advantage in the improvement of the soil characteristics from a geotechnical point of view [3]. Also, thermal pre-treatment of clays may have a very positive effect on their resilience under cyclic loading, which results in a higher resistance of the building's foundations against earthquakes [4]. Such important topics push for additional efforts that should be made to develop predictive capabilities of the effect of heating on the cyclic mobility of soils.

Cyclic response of soils is complex due to the pressure and specific volume dependency on the stress-strain relationship and the highly non-linear behaviour of the soil matrix. This is particularly the case under undrained conditions, where repeated loading and unloading can lead to a substantial rise in pore water pressure and a loss in the shear strength and the stiffness of the soil $[5,6]$.

The constitutive modelling of the cyclic mechanical behaviour of soils under isothermal conditions is a major area of research in geomechanics. Several models already exist (see, for example, the list of models mentioned in Pastor et al. [7], Zienkiewicz et al. [8], Elgamal et al. [9] and in Khalili et al. [5]). However, to the authors' knowledge, none of the existing cyclic models take into account the non-isothermal conditions.

A number of models are available for the constitutive simulation of the heat effect on soils for monotonic rate-independent loading conditions [10-13] and for rate-dependent loading conditions [14].

This paper deals with the non-isothermal constitutive modelling of the capacity of clayey soils to withstand a progressive pore water pressure build-up, induced by a progressive compaction of soils under cyclic loading, and potentially leading to failure. Motivated by experimental observations, a non-isothermal model is formulated using multi-surface thermo-plasticity and is presented in a critical state framework with a non-associative flow rule. It allows the characteristics of cyclic behaviour of soils at different temperatures to be captured. The application and validity of the model are demonstrated using two series of experimental data.

\section{HEAT-INDUCED EFFECTS}

The mechanisms of heat effects on cyclic mobility may be illustrated by undrained stress-controlled cyclic triaxial tests at two temperatures [4]. Figure 2 shows the following aspects:

- the material exhibits a substantially increased resilience to cyclic loading after heating; 

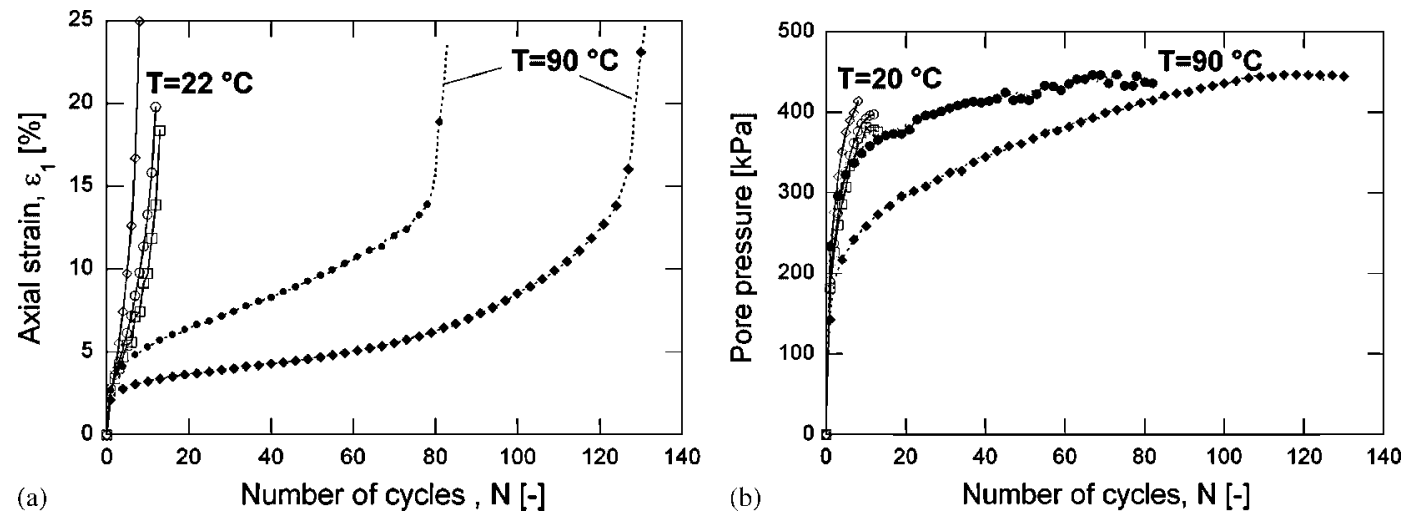

Figure 2. Axial strain (a) and excess pore water pressure (b) as a function of number of cycles for a Kaolin clay in a stress-controlled, undrained triaxial test at ambient $\left(22^{\circ} \mathrm{C}\right)$ and high $\left(90^{\circ} \mathrm{C}\right)$ temperatures.

Three tests were run at $22^{\circ} \mathrm{C}$ and two at $90^{\circ} \mathrm{C}$.

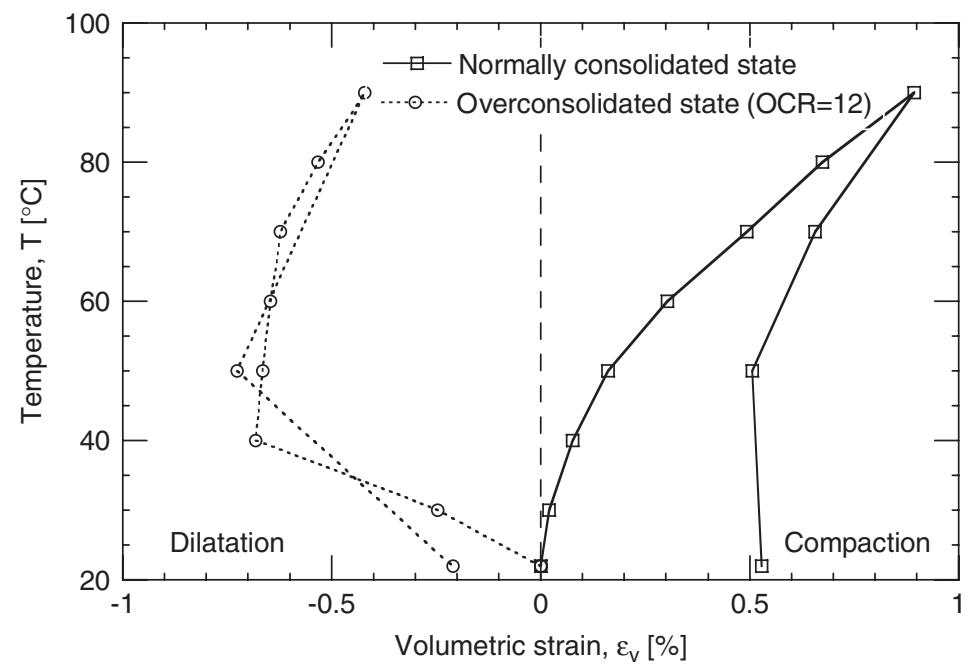

Figure 3. Typical thermal behaviour of Kaolin clay during a drained heating-cooling cycle at constant isotropic stress.

- clearly, the pore pressure developed per single cycle is much smaller after heating;

- the number of cycles to failure increases from nearly 10 at $22^{\circ} \mathrm{C}$ to 100 at $90^{\circ} \mathrm{C}$.

The difference in the mechanical response is to be related to the heat effect. When a clayey soil is heated, under normally consolidated (NC) conditions, it contracts and a significant part of this deformation is irreversible upon cooling [15]. Figure 3 illustrates such results: the response to a heating-cooling cycle at constant isotropic stress of a sample of saturated, drained Kaolin [16]. After heating, the NC sample settles with a non-linear volume variation, while cooling results in volume increase. The behaviour over the whole cycle indicates the irreversibility of strain due 
to thermal loading, which is representative of thermal hardening. Even though there has been no physical change in effective stresses, this can be interpreted as the soil undergoing densification, i.e. overconsolidated (OC) behaviour. The highly OC sample produces mainly reversible dilation. The intensity of the reversible/irreversible parts of the deformation due to temperature cycling depends upon soil type and plasticity, in addition to stress level measured in terms of over consolidation ratio (OCR) [15]. A conceptual analysis of the heat-induced effect could be summarized by the fact that when two initially similar samples are subjected to two different temperatures, they will exhibit different void ratios and will give different resilient behaviour to cyclic loading. This paper aims to reproduce numerically this non-isothermal cyclic-mobility behaviour. A constitutive model is presented in which a coupling is made between a stress-strain cyclic model and a thermo-plastic model.

\section{CYCLIC THERMO-MECHANICAL CONSTITUTIVE MODEL}

For the range of temperatures between 5 and $90^{\circ} \mathrm{C}$, thermal effects on saturated clayey soils are characterized by non-linearity and plasticity $[3,12,15]$. Such rheological aspects may be mathematically formulated in the elasto-plasticity framework $[10,17,18]$. Temperature is considered as a state parameter which induces elastic and plastic strains.

- Thermo-elasticity is classically expressed by a superposition of the reversible thermal strain on the mechanical one.

- Thermo-plasticity can be expressed through a thermal hardening which results in different stress-strain behaviour for different temperatures.

The constitutive model proposed here uses a multiple plasticity approach [19,20]. It couples an isotropic thermo-plastic model describing behaviour in the temperature-mean effective pressure plane [12], to a cyclic deviatoric model, describing strength and volume variation during cyclic shearing [14, 21, 22]. This model works for small and large strain ranges and incorporates contractive and dilative properties. The isotropic thermo-plastic mechanism allows the consideration of heat effects on behaviour and the description of the material stress-strain state at any temperature. Then, starting from such a state (at a given temperature), the deviatoric mechanisms are able to describe the cyclic behaviour under non-isothermal conditions. The model is based on non-linear elasticity and four elementary elasto-plastic mechanisms: one isotropic thermo-plastic and three cyclic deviatoric mechanisms. It is expressed using effective stresses so that undrained tests can be considered as isochoric strain paths (constant volume).

The total strain increment, $\dot{\varepsilon}_{i j}$, is written as

$$
\dot{\varepsilon}_{i j}=\dot{\varepsilon}_{i j}^{\mathrm{Te}}+\dot{\varepsilon}_{i j}^{\mathrm{Tp}}
$$

where the superscripts $\mathrm{Te}$ and $\mathrm{Tp}$ indicate thermo-elastic and thermo-plastic components of the strain, respectively.

\subsection{Thermo-elasticity}

The thermo-elastic strain rate, $\dot{\varepsilon}_{i j}^{\mathrm{Te}}$, is composed of the superposition of a mechanical hypo-elastic strain rate under adiabatic conditions, $\dot{\varepsilon}_{i j}^{\mathrm{e}}$, and a reversible thermal dilation rate, $\dot{\varepsilon}_{i j}^{\mathrm{T}}$. The volumetric 
and deviatoric parts are

$$
\dot{\varepsilon}_{v}^{\mathrm{Te}}=\frac{\dot{p}^{\prime}}{K}+\beta_{\mathrm{s}}^{\prime} \dot{T}, \quad \dot{\varepsilon}_{i j}^{\mathrm{ed}}=\frac{\dot{\sigma}_{i j}^{\mathrm{d}}}{G}
$$

$\dot{\varepsilon}_{v}^{\mathrm{Te}}$ is the thermo-elastic volumetric strain rate $\left(\dot{\varepsilon}_{v}^{\mathrm{Te}}=\operatorname{tr}\left(\dot{\varepsilon}_{i j}^{\mathrm{Te}}\right)\right)$ and $\dot{\varepsilon}_{i j}^{\mathrm{ed}}$ the deviatoric elastic strain rate $\left(\dot{\varepsilon}_{i j}^{\text {ed }}=\dot{\varepsilon}_{i j}^{\mathrm{e}}-\frac{1}{3} \dot{\varepsilon}_{v}^{\mathrm{e}} \delta_{i j}\right) ; \dot{\sigma}_{i j}^{\mathrm{d}}$ and $\dot{p}^{\prime}$ are the deviatoric effective stress rate and the mean effective pressure rate, respectively, expressed as

$$
\dot{\sigma}_{i j}^{\mathrm{d}}=\dot{\sigma}_{i j}^{\prime}-\dot{p}^{\prime} \delta_{i j}, \quad \dot{p}^{\prime}=\operatorname{tr}\left(\dot{\sigma}_{i j}^{\prime}\right) / 3
$$

$\dot{\sigma}_{i j}^{\prime}$ is the effective stress tensor and $\delta_{i j}$ is the Kroenecker symbol. The thermal expansion coefficient of the solid skeleton, $\beta_{\mathrm{s}}^{\prime}$, varies strongly with temperature and slightly with pressure according to

$$
\beta_{\mathrm{s}}^{\prime}=\left(\beta_{\mathrm{s} 0}^{\prime}+\zeta T\right) \xi
$$

in which $\beta_{\mathrm{s} 0}^{\prime}$ is the isotropic thermal expansion coefficient at a reference temperature, $T_{0}$ (usually ambient temperature), and $\xi$ the ratio between the initial critical state pressure, $p_{\mathrm{c} 0}$, and the mean effective pressure, $p^{\prime}$, at ambient temperature:

$$
\xi=\frac{p_{\mathrm{c} 0}}{p^{\prime}}
$$

$\zeta$ corresponds to the slope of the variation of $\beta_{\mathrm{s}}^{\prime}$ with respect to current temperature, $T$, at $\xi=1$. The hypo-elastic moduli are given by

$$
K=K_{\text {ref }}\left(\frac{p^{\prime}}{p_{\text {ref }}}\right)^{n}, \quad G=G_{\text {ref }}\left(\frac{p^{\prime}}{p_{\text {ref }}}\right)^{n}
$$

where $K_{\text {ref }}$ and $G_{\text {ref }}$ are the bulk and shear elastic moduli, respectively, at a reference pressure, $p_{\text {ref }}$ (the value of the mean effective pressure at which the hypo-elastic moduli are measured); $n$ being a material constant.

\subsection{Thermo-plasticity}

3.2.1. Isotropic thermo-plastic mechanism. The yield limit, $f_{\mathrm{Ti}}$, of the isotropic thermo-plastic mechanism is represented in the mean effective stress $p^{\prime}$-temperature $T$ plane (Figure 4 ) and it is expressed by

$$
f_{\mathrm{Ti}}=p^{\prime}-\sigma_{\mathrm{c}}^{\prime}
$$

where $\sigma_{\mathrm{c}}^{\prime}$ is the isotropic preconsolidation pressure (highest stress ever experienced by the material) expressed as a function of the volumetric plastic strain, $\varepsilon_{v}^{\mathrm{p}}$, and the temperature:

$$
\sigma_{\mathrm{c}}^{\prime}=\sigma_{\mathrm{c}}^{\prime}(T) \exp \left\{\beta \varepsilon_{v}^{\mathrm{p}}\right\}
$$

where $\sigma_{\mathrm{c}}^{\prime}(T)$ is the value of the preconsolidation pressure at the temperature $T$ and $\beta$ is the plastic compressibility modulus (the slope of the linear function $\varepsilon_{v}^{\mathrm{p}}-\log \sigma_{\mathrm{c}}^{\prime}$ ). A dependency law for the thermal evolution of the preconsolidation pressure, $\sigma_{\mathrm{c}}^{\prime}(T)$, is introduced to take into account the thermal effect on the yield limit:

$$
\sigma_{\mathrm{c}}^{\prime}(T)=\sigma_{\mathrm{c}}^{\prime}\left(T_{0}\right)\left\{1-\gamma \log \left[T / T_{0}\right]\right\}
$$




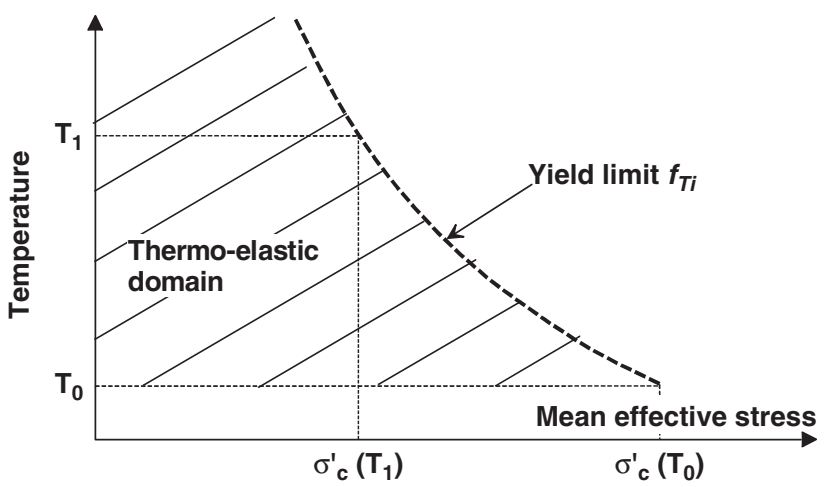

Figure 4. Isotropic thermo-plastic yield limit.

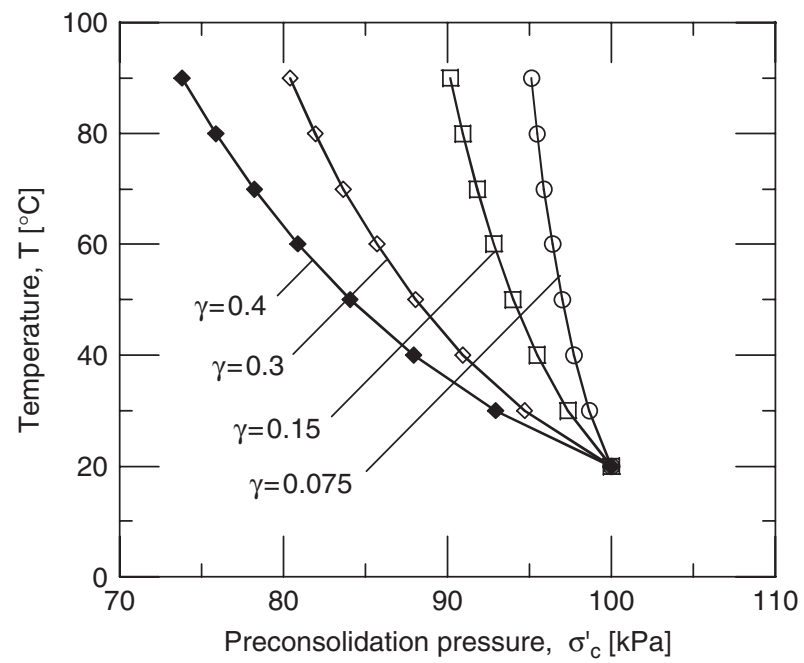

Figure 5. Shape of the isotropic thermo-plastic yield limit for different values of the parameter $\gamma$.

where $\sigma_{\mathrm{c}}^{\prime}\left(T_{0}\right)$ is the value of the preconsolidation pressure at the reference temperature, $T_{0}$, and $\gamma$ is a material parameter.

The expression of the isotropic thermo-plastic yield limit is thus given by

$$
f_{\mathrm{Ti}}=p^{\prime}-\sigma_{\mathrm{c}}^{\prime}\left(T_{0}\right) \exp \left\{\beta \varepsilon_{v}^{\mathrm{p}}\right\}\left\{1-\gamma \log \left[T / T_{0}\right]\right\}
$$

Equation (10) contains two material parameters: $\beta$ expressing the evolution of the mechanical hardening and $\gamma$ controlling the evolution of the thermal hardening. This latter one defines the shape of the yield limit as shown in Figure 5.

The numerical predictions obtained with this isotropic thermo-plastic mechanism compare favourably with experimental results and the produced thermal strains fit the observed 
results well [12]. This allows a good description of the stress-strain state of the material at any temperature.

3.2.2. Deviatoric cyclic plastic mechanisms. Starting from a given state of the material corresponding to a given temperature (obtained using the thermo-plastic isotropic mechanism), the deviatoric mechanisms describe the strength and the volume variation of the material under deviatoric cyclic mechanical loading. They are based on the concept of hardening moduli introduced by Mroz et al. [23]. In the following sections, the monotonic loading conditions are designated by the letter ' $\mathrm{m}$ ' and the cyclic loading conditions by the letter ' $c$ '.

Monotonic yield surface: Three deviatoric yield surfaces are written in three orthogonal planes (mechanisms $k ; k=\{1,2,3\}$ ) of the stress space. In each plane, a plane plastic strain hypothesis is assumed and a limit criterion very close to that of Mohr-Coulomb is obtained; its yield function is close to that of original Cam-Clay. Thus, the deviatoric monotonic yield surface for any mechanism $k$ is proposed as

$$
f_{k}^{\mathrm{m}}=q_{k}-p_{k}\left(1-b \ln \frac{p_{k}}{p_{\mathrm{c}}}\right) r_{k}^{\mathrm{m}} \sin \phi
$$

where $p_{k}$ and $q_{k}$ are the reduced mean effective pressure and deviatoric stress, respectively, in the plane of each deviatoric mechanism $k$, given as

$$
q_{k}=\left\|\mathbf{S}_{\mathbf{k}}\right\|=\frac{1}{2}\left[\left(\sigma_{i i}^{\prime}-\sigma_{j j}^{\prime}\right)^{2}+4 \sigma_{i j}^{\prime 2}\right]^{1 / 2}, \quad p_{k}=\frac{\left(\sigma_{i i}^{\prime}+\sigma_{j j}^{\prime}\right)}{2}
$$

where $k=\{1,2,3\} ; i, j=\{2,3\},\{3,1\},\{1,2\}$ and $b$ is a parameter which controls the shape of the yield surface ( $b=0$ for Mohr-Coulomb; $b=1$ for Cam-Clay); $\phi$ is the friction angle at the critical state and $\mathbf{s}_{\mathbf{k}}=\left(\frac{1}{2}\left(\sigma_{i i}^{\prime}-\sigma_{j j}^{\prime}\right), \sigma_{i j}^{\prime}\right)_{k}$. In Equation (11), the internal variable $r_{k}^{\mathrm{m}}$ represents the ratio of the mobilized friction over the maximum friction which may be mobilized. It permits the decomposition of the behaviour domain into elastic, hysteretic and mobilized domains introduced by other model parameters termed $r_{\mathrm{el}}, r_{\text {hys }}$ and $r_{\text {mob }}$.

$p_{\mathrm{c}}\left(p_{\mathrm{c}}=p_{\mathrm{c} 0} \exp \beta \varepsilon_{v}^{\mathrm{Tp}}\right)$ is the critical pressure; $p_{\mathrm{c} 0}$ is the initial critical pressure related to the preconsolidation pressure $\sigma_{\mathrm{c}}^{\prime}$ by

$$
p_{\mathrm{c}}=\frac{\sigma_{\mathrm{c}}^{\prime}}{d}
$$

where $d$ represents, by neglecting the elastic part of the strain, the distance in the void ratio-log mean effective stress plane, the straight line representing the critical state and the parallel one representing the isotropic consolidation line $(d=\exp (1)$ in the original Cam-Clay). The isotropic thermo-plastic mechanism is coupled with the deviatoric mechanisms through the evolution of the preconsolidation pressure $\sigma_{\mathrm{c}}^{\prime}$ (Figure 6).

The deviatoric part of the model contains two isotropic hardening parameters: the volumetric plastic strain, $\varepsilon_{v}^{\mathrm{Tp}}$, and the internal variable $r_{k}^{\mathrm{m}}$. However, they have different evolution rules and different origins, as well. The first one introduces the isotropic hardening associated with the thermo-plastic volumetric strain. The second one represents the isotropic hardening caused by the deviatoric plastic strain in each mechanism. The mechanisms are coupled only due to the first one, as the second is attached to each physical plane representing the deviatoric mechanism. 


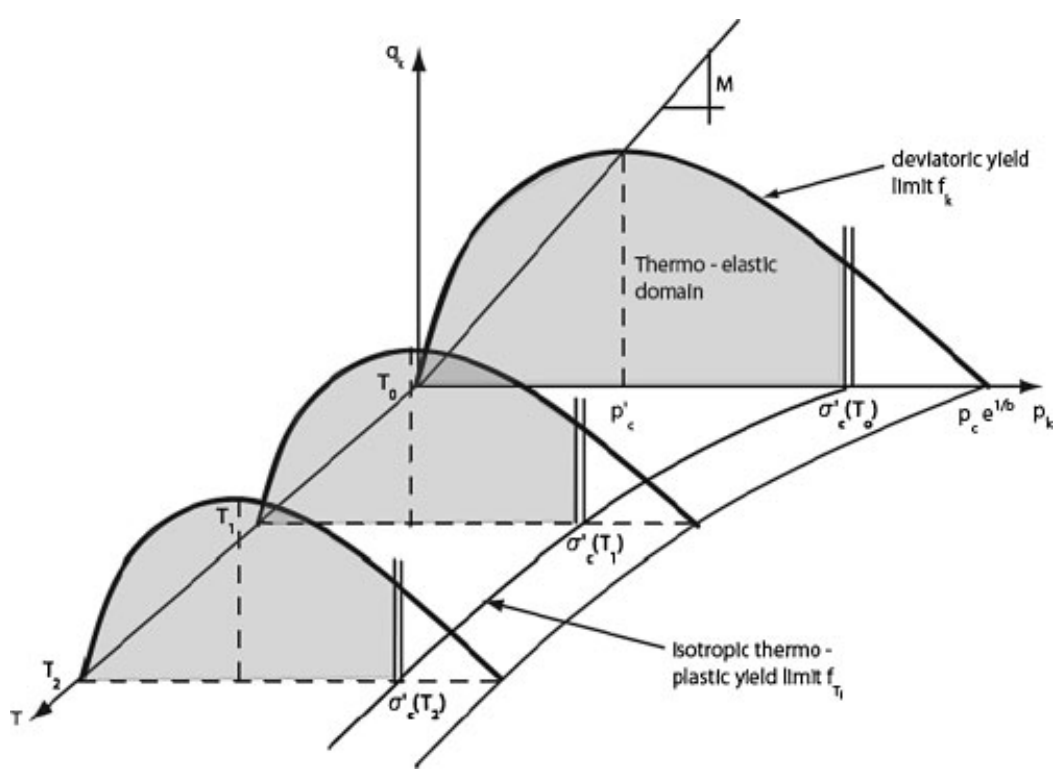

Figure 6. Coupled thermo-plastic yield limits.

Cyclic yield surfaces: In the same way as for the monotonic yield limits, the cyclic yield surfaces are written as

$$
f_{k}^{\mathrm{c}}=q_{k}^{\mathrm{c}}-p_{k}\left(1-b \ln \frac{p_{k}}{p_{\mathrm{c}}}\right) r_{k}^{\mathrm{c}} \sin \phi
$$

with

$$
q_{k}^{\mathrm{c}}=\left\|\mathbf{s}_{\mathbf{k}}^{\mathrm{c}}\right\|=\left\|\mathbf{s}_{\mathbf{k}}-p_{k}\left(1-b \ln \frac{p_{k}}{p_{\mathrm{c}}}\right) \sin \phi\left(\mathbf{D}_{\mathbf{k}}-\mathbf{n}_{\mathbf{k}} r_{k}^{\mathrm{c}}\right)\right\|
$$

where $\mathbf{D}_{\mathbf{k}}$ is the normalized stress tensor at the unloading or reloading point and $\mathbf{n}_{\mathbf{k}}$ the exterior normal vector with respect to the active yield limit at this point.

To illustrate the yield limit evolution, the normalized form with respect to $p_{k}\left(1-b \ln p_{k} / p_{\mathrm{c}}\right) \sin \phi$ may be used:

$$
\Im_{k}^{c}=\left\|\tilde{\mathbf{s}}_{\mathbf{k}}-\left(\mathbf{D}_{\mathbf{k}}-\mathbf{n}_{\mathbf{k}} r_{k}^{\mathrm{c}}\right)\right\|-r_{k}^{\mathrm{c}}
$$

where

$$
\tilde{\mathbf{s}}_{\mathbf{k}}=\frac{\mathbf{s}_{\mathbf{k}}}{p_{k}\left(1-b \ln \frac{p_{k}}{p_{\mathrm{c}}}\right) \sin \phi}
$$

During primary loading, the deviatoric yield surfaces are concentric circles that can be activated when the stress point leaves the initial elastic domain $\left(r_{\mathrm{el}}\right)$. The stress tensor at the point where loading changes direction, $\mathbf{D}_{\mathbf{k 1}}$, defines the maximal 'historic' yield surface (Figure 7). The exterior normal on the yield surface at this point is the vector $\mathbf{n}_{\mathbf{k} \mathbf{1}}$. 


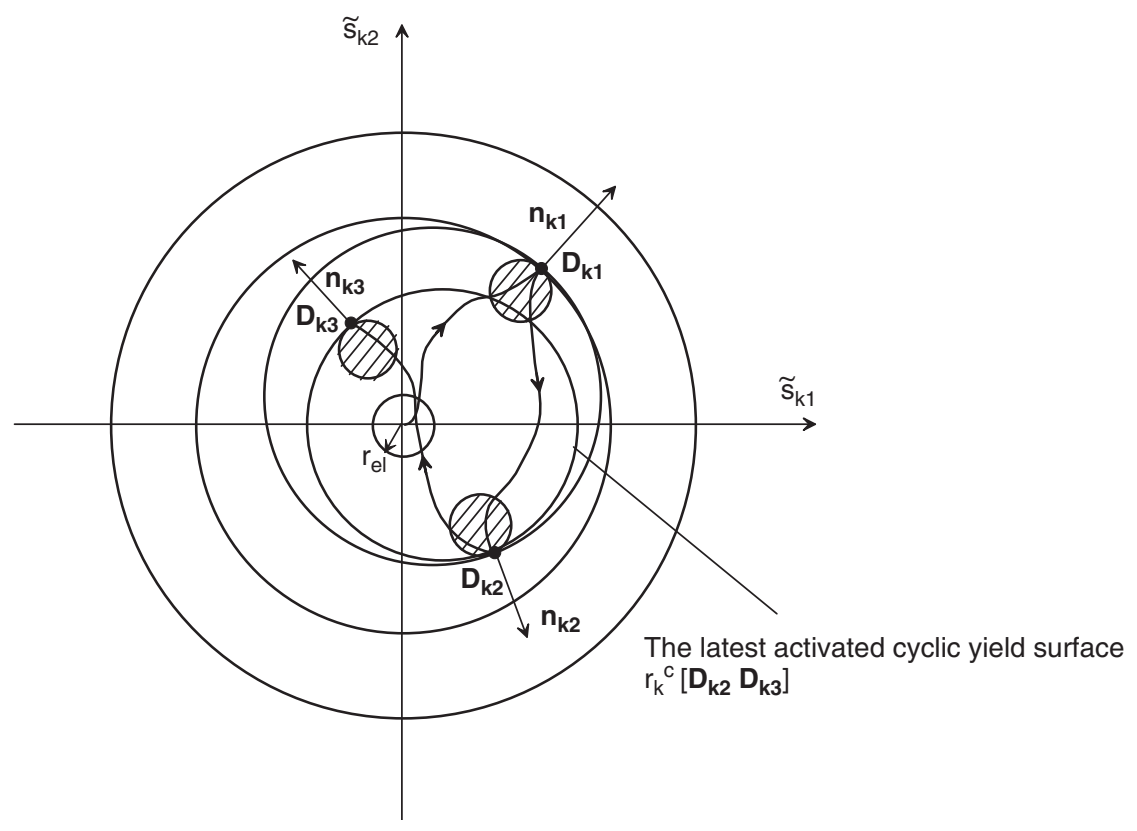

Figure 7. Evolution of the yield surfaces during the cyclic loading in the normalized plane $\left(\tilde{s}_{k 1}, \tilde{s}_{k 2}\right)$ for a deviatoric mechanism $k$.

During the first cyclic loading, the stress point enters the 'historic' yield surface. The successive yield surfaces that can be activated are prescribed by the last stress tensor $\mathbf{D}_{\mathbf{k} \mathbf{1}}$, the exterior normal $\mathbf{n}_{\mathbf{k} \mathbf{1}}$ and the actual stress point. The new point where stress changes direction is $\mathbf{D}_{\mathbf{k} \mathbf{2}}$ and the corresponding normal $\mathbf{n}_{\mathbf{k} 2}$ gives the latest activated cyclic yield surface (Figure 7). The subsequent loading enters the latest activated yield surface until the stress point changes direction $\left(\mathbf{D}_{\mathbf{k} 3}\right)$, giving the new latest cyclic yield surface, and so on. If the actual yield surface touches the 'historic' yield surface, then the monotonic mechanism will be activated.

The tensor $\mathbf{D}_{\mathbf{k}}$, vector $\mathbf{n}_{\mathbf{k}}$ and radius of the latest yield surface $r_{k}^{\mathrm{c}}$ are reinitialized for each change in loading direction. Also, they are reinitialized when the cyclic yield surface becomes tangent to the monotonic ('historic') yield surface. The new values of $\mathbf{D}_{\mathbf{k}}$ and $\mathbf{n}_{\mathbf{k}}$ are taken at the tangent points of the two cycles. Therefore, each mechanism has the following memory parameters:

- $r_{k}^{\mathrm{m}}$ the maximal degree of mobilization of the monotonic mechanism, which is the 'historic' memory parameter;

- $\mathbf{D}_{\mathbf{k}}$ and $\mathbf{n}_{\mathbf{k}}$ are memories of the last change in loading direction, which are instantaneous memory parameters.

Plastic flow rule for monotonic and cyclic loading conditions: The volumetric thermo-plastic strain rate of the isotropic mechanism, $\dot{\varepsilon}_{v i}^{\mathrm{Tp}}$, is expressed through the following consistency equation:

$$
\dot{f}_{\mathrm{Ti}}=\partial_{p^{\prime}} f_{\mathrm{Ti}} \dot{p}^{\prime}+\partial_{T} f_{\mathrm{Ti}} \dot{T}+\partial_{\varepsilon_{v i}^{\mathrm{Tp}}} f_{\mathrm{Ti}} \dot{\varepsilon}_{v i}^{\mathrm{Tp}}=0
$$


Thus,

$$
\dot{\varepsilon}_{v i}^{\mathrm{Tp}}=-\frac{\partial_{p^{\prime}} f_{\mathrm{Ti}} \dot{p}^{\prime}+\partial_{T} f_{\mathrm{Ti}} \dot{T}}{\partial_{\varepsilon_{v i}^{\mathrm{Tp}}} f_{\mathrm{Ti}}}
$$

The plastic flow rule is also derived for each deviatoric mechanism $k$, and the plastic strain rate tensor is expressed by its trace (first invariant), $\left(\dot{e}_{v}^{\mathrm{Tp}}\right)_{k}$, and the vector $\left(\dot{\mathbf{e}}_{d}^{\mathrm{Tp}}\right)_{k}$, both defined by

$$
\begin{aligned}
& \left(\dot{e}_{v}^{\mathrm{Tp}}\right)_{k}=\left(\dot{\varepsilon}_{i i}^{\mathrm{Tp}}+\dot{\varepsilon}_{j j}^{\mathrm{Tp}}\right)_{k}=\dot{\lambda}_{k} \cdot\left(\Psi_{v}\right)_{k}, \\
& \left(\dot{\mathbf{e}}_{d}^{\mathrm{Tp}}\right)_{k}=\left(\left(\dot{\varepsilon}_{i i}^{\mathrm{Tp}}-\dot{\varepsilon}_{j j}^{\mathrm{Tp}}\right), \dot{\varepsilon}_{i j}^{\mathrm{Tp}}\right)_{k}=\dot{\lambda}_{k} \cdot\left(\Psi_{d}\right)_{k},
\end{aligned}
$$

For the deviatoric component, $\left(\dot{\mathbf{e}}_{d}^{\mathrm{Tp}}\right)_{k}$, the direction of plastic flow in each mechanism is obtained by assuming the normality rule in the deviatoric plane. For the volumetric component, a modified Roscoe's dilatancy rule is applied [24]. $\left(\Psi_{v}\right)_{k}$ and $\left(\Psi_{d}\right)_{k}$ are thus defined for monotonic (m) as well as for cyclic (c) conditions by

$$
\begin{aligned}
& \left(\Psi_{v}\right)_{k}=-\alpha_{k}^{\Xi}\left(\sin \psi-\frac{\left[\mathbf{s}_{\mathbf{k}} \cdot\left(\Psi_{d}\right)_{k}\right]}{p_{k}}\right), \quad \Xi=\text { m or c } \\
& \left(\Psi_{d}\right)_{k}=\partial_{\mathbf{s}_{\mathbf{k}}} f_{k}^{\Xi},
\end{aligned}
$$

where $\psi$ is the dilatancy angle corresponding to the characteristic line. The plastic multipliers $\dot{\lambda}_{k}$ are evaluated from persistency (or consistency) conditions:

$$
\dot{\lambda}_{k} \dot{f}_{k}=0
$$

The parameter $\alpha_{k}^{\Xi}$ adjusts dilatancy during shearing, which may vary with $r_{k}^{\Xi}$ depending on the domain of mechanical behaviour (for soft clays, $\alpha_{k}^{\Xi}$ is close to 1 ). When introducing the evolution law for the internal variable $\dot{r}_{k}^{\Xi}$ :

$$
\dot{r}_{k}^{\Xi}=\dot{\lambda}_{k} l^{\Xi}
$$

where $l^{\Xi}$ is a constitutive function expressed by

$$
l^{\mathrm{m}}=\frac{\left(1-r_{k}^{\mathrm{m}}\right)^{2}}{a\left(r_{k}\right)}
$$

and

$$
l^{\mathrm{c}}=\frac{\left(1-r_{k}^{\mathrm{c}}\right)^{2}}{a\left(r_{k}\right)} \frac{\left\|\mathbf{s}_{\mathbf{k}}^{\mathrm{c}}\right\|}{\left\|\mathbf{s}_{\mathbf{k}}^{\mathrm{c}}\right\|-\mathbf{n}_{\mathbf{k}} \mathbf{s}_{\mathbf{k}}^{\mathrm{c}}}
$$

for monotonic and cyclic conditions, respectively; $a\left(r_{k}\right)$ is a parameter defined as

$$
a\left(r_{k}\right)=a_{\mathrm{c}}+\left(a_{\mathrm{m}}-a_{\mathrm{c}}\right) \alpha_{k}^{\Xi}
$$

Undrained paths: As the model is expressed using effective stresses, the undrained tests can be considered as isochoric strain paths (constant volume). Based on a continuum approach of the 
mass conservation for a saturated two-phase mixture, it is possible to derive Biot's equation [25] expressing the pore water pressure during mechanical loading (by neglecting the convective terms):

$$
\vartheta \beta_{f} \partial_{t} p_{f}=-\dot{\varepsilon}_{v}
$$

$\vartheta$ is the porosity; $p_{f}$ the pore water pressure and $\beta_{f}$ the water compressibility coefficient at constant temperature, respectively; $\dot{\varepsilon}_{v}$ is the total volumetric strain:

$$
\dot{\varepsilon}_{v}=\dot{\varepsilon}_{v}^{\mathrm{Te}}+\dot{\varepsilon}_{v i}^{\mathrm{Tp}}+\sum_{k=1}^{3}\left(\dot{e}_{v}^{\mathrm{Tp}}\right)
$$

Therefore, the variation of the water pore pressure is attributed to the variation of the skeletal volume (compaction or dilation).

\section{NUMERICAL PERFORMANCES}

The numerical performances of the constitutive model are presented in this section through the simulation of the laboratory experimental results on Kaolin clay and MC clay.

\subsection{Simulation of the behaviour of Kaolin clay}

The simulations carried out are based on experimental results obtained from Kaolin reconstituted samples [3]. Samples were obtained by mixing de-aired distilled water with clay powder at a water content two times the liquid limit of the soil. After preparation, isotropic consolidation of the slurry was carried out under a confining pressure of $100 \mathrm{kPa}$. The soil samples were then obtained by trimming the clay cakes. The properties of the Kaolin clay are given in Table I.

In order to quantify the influence of temperature on cyclic stress-strain behaviour, two series of tests were performed [4]. One series consisted of cyclic shear tests in undrained conditions at constant ambient temperature. Before being sheared, the samples were consolidated at a mean effective pressure of $600 \mathrm{kPa}$. Three tests were carried out under the same conditions in order to check the scatter of the experimental results. The second set of samples were consolidated to $600 \mathrm{kPa}$, and then heated in drained conditions to $90^{\circ} \mathrm{C}$. Thereafter, the samples were cyclically sheared in undrained conditions at this temperature.

In both cases, one-way tests, in which the deviatoric stress $q$ is cycled between zero and the deviator stress $q_{m}$, were carried out. In the case of tests carried out at ambient temperature, the single amplitude of the deviator stress was about $290 \mathrm{kPa}$ applied for $1 \mathrm{~h}$. However, for shear tests carried out at high temperature, the control of the deviator stress is much more difficult. Therefore, in spite of the fact that the applied stress (imposed by electronic controllers, see Cekerevac et al. [26]) was chosen to cycle the deviator stress between zero and $290 \mathrm{kPa}$, the measured deviator stress varied between 30 and about $330 \mathrm{kPa}$.

Table I. Properties of the Kaolin and MC clays.

\begin{tabular}{lccccc}
\hline & $w_{\mathrm{L}}(\%)$ & $w_{\mathrm{p}}(\%)$ & $I_{\mathrm{p}}$ & $\%<2 \mu \mathrm{m}$ & $\gamma_{\mathrm{s}}\left(\mathrm{kN} / \mathrm{m}^{3}\right)$ \\
\hline Kaolin clay & 45 & 21 & 24 & 45 & 25.8 \\
MC clay & 70 & 41 & 29 & 49 & 26.98 \\
\hline
\end{tabular}


Table II. Model parameters.

\begin{tabular}{|c|c|}
\hline Model part & $\begin{array}{l}\text { Parameters for the Kaolin clay } \\
\text { Parameters for the MC clay }\end{array}$ \\
\hline Elastic & $\begin{array}{l}K_{\text {ref }}=70 \mathrm{MPa}, G_{\text {ref }}=30 \mathrm{MPa}, n=0.68(\text { Equation }(6)) \\
K_{\text {ref }}=80 \mathrm{MPa}, G_{\text {ref }}=37 \mathrm{MPa}, n=0.5\end{array}$ \\
\hline Plastic & $\begin{array}{l}\phi=20.9^{\circ} / 23.4^{\circ}, \beta=21, p_{\mathrm{c} 0}=0.22 \mathrm{MPa} \text { (Equation (11)) } \\
\phi=18^{\circ}, \beta=11, p_{\mathrm{c} 0}=0.1 \mathrm{MPa}\end{array}$ \\
\hline Dilatancy & $\begin{array}{l}\psi=21.5^{\circ} \text { (Equation (19)) } \\
\psi=18^{\circ}\end{array}$ \\
\hline Hardening & $\begin{array}{l}b=0.5, d=2.1 \text { (Equations (11) and (13)) } \\
a_{\mathrm{m}}=0.0035, a_{\mathrm{c}}=0.0004 \text { (Equation (25)) } \\
b=0.9, d=2.1 \\
a_{\mathrm{m}}=0.006, a_{\mathrm{c}}=0.005\end{array}$ \\
\hline Domains & $\begin{array}{l}r_{\mathrm{el}}=0.001, r_{\mathrm{hys}}=0.01, r_{\mathrm{mbl}}=0.4 \\
r_{\mathrm{el}}=0.001, r_{\mathrm{hys}}=0.2, r_{\mathrm{mbl}}=0.9\end{array}$ \\
\hline Thermal & $\begin{array}{l}\beta_{\mathrm{s} 0}^{\prime}=3 \mathrm{E}-5^{\circ} \mathrm{C}^{-1}, \beta_{\mathrm{f}}=4 \mathrm{E}-4^{\circ} \mathrm{C}^{-1}, \gamma=0.075 \text { (Equations (4), (9), and (26)) } \\
\beta_{\mathrm{s} 0}^{\prime}=3 \mathrm{E}-5^{\circ} \mathrm{C}^{-1}, \beta_{\mathrm{f}}=4 \mathrm{E}-4^{\circ} \mathrm{C}^{-1}, \gamma=0.10\end{array}$ \\
\hline
\end{tabular}

4.1.1. Calibration of model parameters and back-predictions. The material parameters of the Kaolin clay were determined using the following experimental tests: three isotropic consolidation tests at 22,60 and $90^{\circ} \mathrm{C}$, respectively, and two drained shear tests at room temperature at $\mathrm{OCR}=1$ and 12 (Appendix A). The model parameters are summarized in Table II. Predictions of experimental results of drained monotonic shear tests at high temperature, in NC and OC $(\mathrm{OCR}=12)$ states, are shown in Figure 8. As can be observed, the monotonic model simulations are close to the experimental results. For the numerical predictions of the cyclic shear tests, the value of the friction angle was taken to be $23.4^{\circ}$. This value corresponds to the phase transformation line, and it is more appropriate for the modelling of a one-way cyclic shear test than the friction angle of $21^{\circ}$ obtained for the failure line $[27,28]$.

4.1.2. Numerical modelling of cyclic behaviour. At ambient temperature: The comparison between experimental results and numerical predictions of the undrained cyclic shear tests at ambient temperature is shown in Figure 9. As may be seen during the first cycle, significant plastic strains were created. The subsequent cycles retained practically the same shape but they moved along the axial strain axis (Figure 9(a)). The undrained cyclic shear tests led to an increase in pore water pressure until the stress cycle met the line of perfect plasticity and a parallel reduction in the effective stress of the material (Figure 9(b) and (c)). At this point, there was a large increase in strains and a general rupturing of the material. According to Biarez and Hicher [29], liquefaction only occurs with two-way cyclic tests, while one-way tests also produce an increase in pore pressure, but these tend towards stabilization before liquefaction occurs. As a result of pore water 

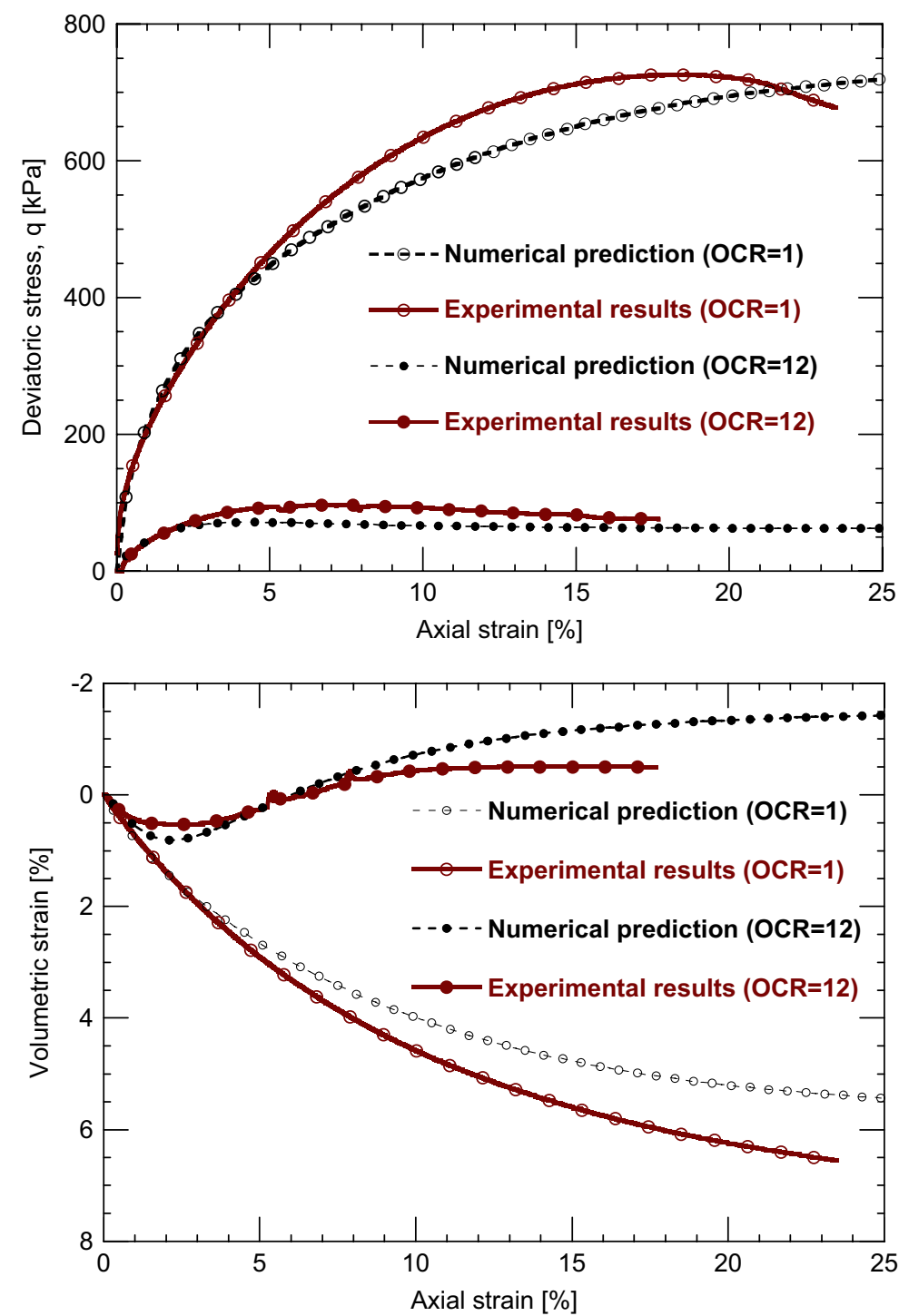

Figure 8. Comparison between experimental results of drained shear tests at high temperature $\left(90^{\circ} \mathrm{C}\right)$ and numerical predictions for the Kaolin clay; the initial OCR values are indicated in the legends.

pressure stabilization, in the $p^{\prime}-q$ plane the cycles stabilized at a mean effective pressure of about $200 \mathrm{kPa}$ (Figure 9(c)). In the deviatoric stress-axial strain plane, the numerical predictions give good results; there is a small gap between the results, however, the number of cycles to an axial strain of $20 \%$ is the same. The numerical predictions of the shear-induced pore water pressure are quite satisfactory and thus the cycles compare fairly well in the $p^{\prime}-q$ plane. 

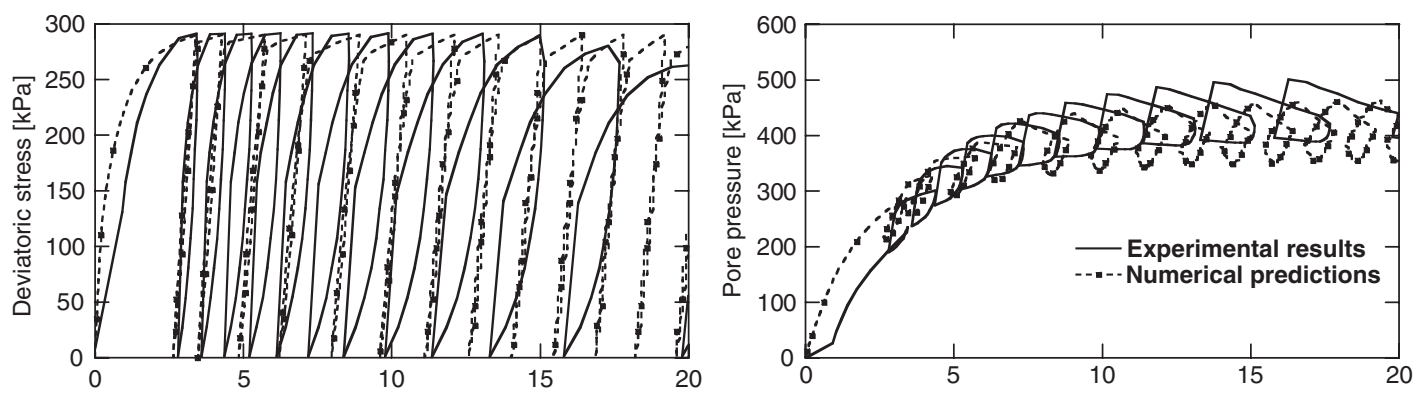

(a)

Axial strain [\%]

(b)

Axial strain [\%]

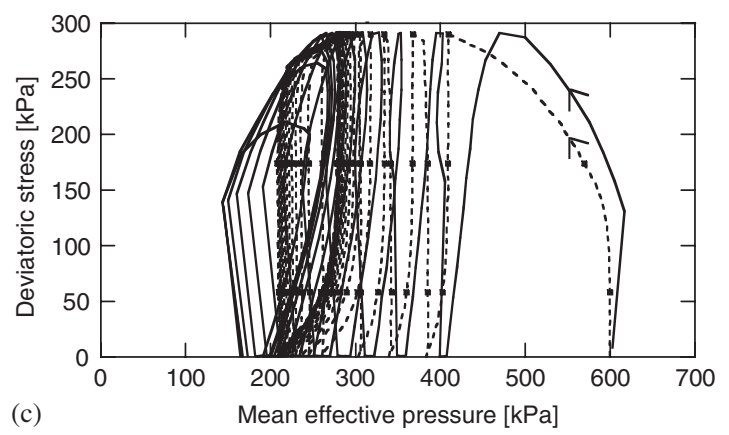

Figure 9. Numerical predictions of cyclic undrained shear tests carried out at ambient temperature: (a) axial strain versus deviatoric stress; (b) axial strain versus pore water pressure; and (c) mean effective pressure versus deviatoric stress-Kaolin clay.

At high temperature: Figure 10 shows the numerical predictions of the undrained cyclic shear tests compared with the experimental results at a temperature of $90^{\circ} \mathrm{C}$. The following comments may be made:

- The model catches the thermal-induced overconsolidation well; it captures the difference in the cyclic stress-strain behaviour at different temperatures and shows that the number of cycles at failure is different from that with no prior heating (Figure 9).

- The model gives steeper and straighter cycles than those at ambient temperature. The predictions underestimate pore water pressure (by about 10\%), which results in a difference in the $p^{\prime}-q$ plane (Figure 10(c)).

In Figures 9 and 10, it could be observed that the numerical results have cycles with constant amplitude while this is the case for the experimental results only until the beginning of the lost of controllability of the experimental tests.

Comparison of undrained cyclic shear tests at 22 and $90^{\circ} \mathrm{C}$ : Figure 11 shows the predictions of the evolution of the axial strain and pore water pressure with respect to the number of cycles at ambient and high temperatures compared with the experimental measurements. The following principal comments may be made.

- The model reproduces the straightening of the heated material. 

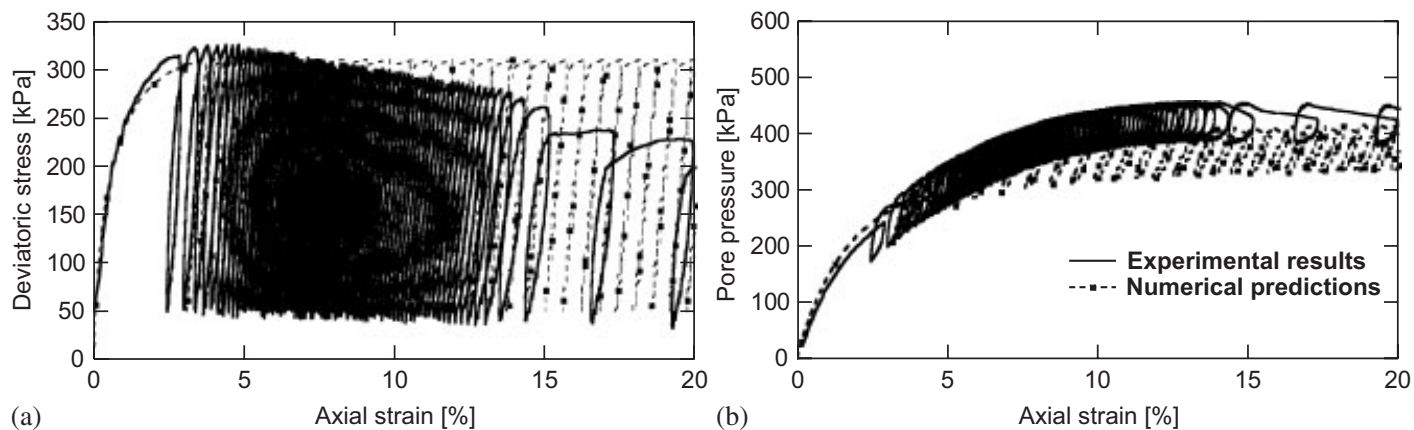

(a) Axial strain [\%]

(b)

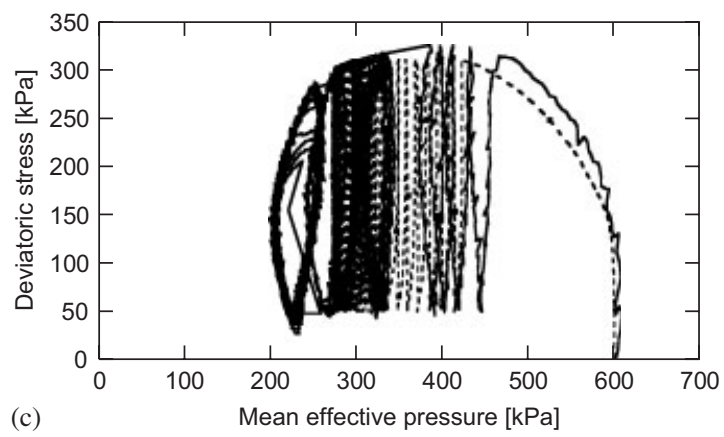

Figure 10. Numerical predictions of cyclic undrained shear tests carried out at high temperature $\left(90^{\circ} \mathrm{C}\right)$ : (a) axial strain versus deviatoric stress; (b) axial strain versus pore water pressure; and (c) mean effective pressure versus deviatoric stress-Kaolin clay.
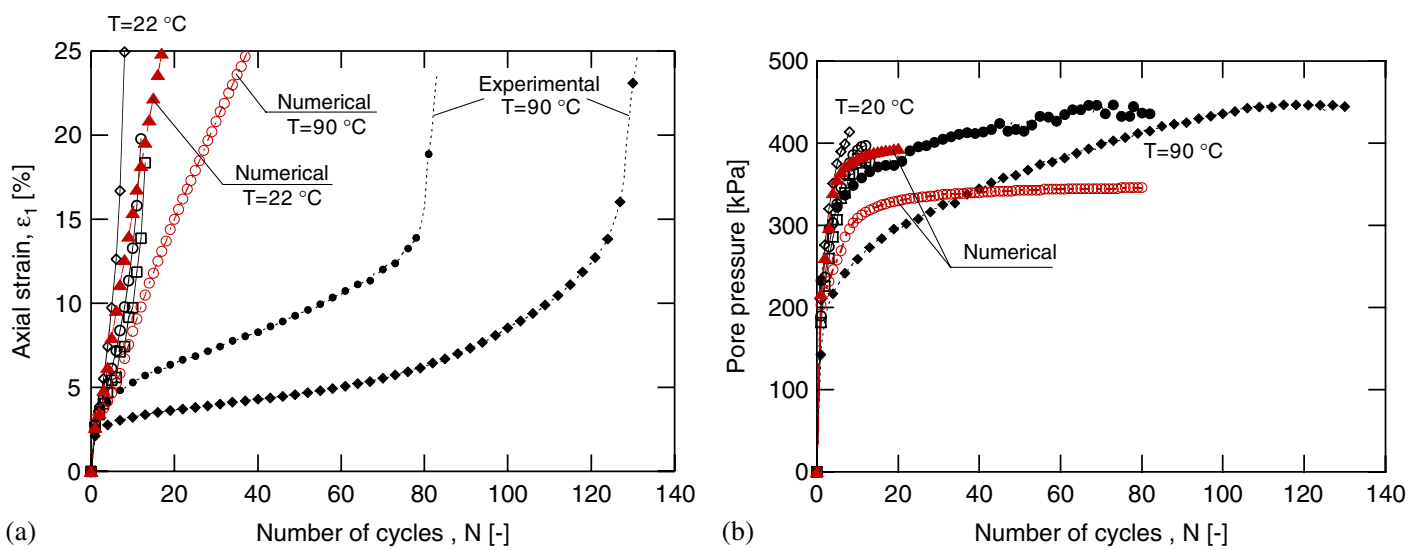

Figure 11. Cyclic undrained triaxial shear tests at 22 and $90^{\circ} \mathrm{C}$ on Kaolin clay-comparison between experimental results and numerical predictions. 


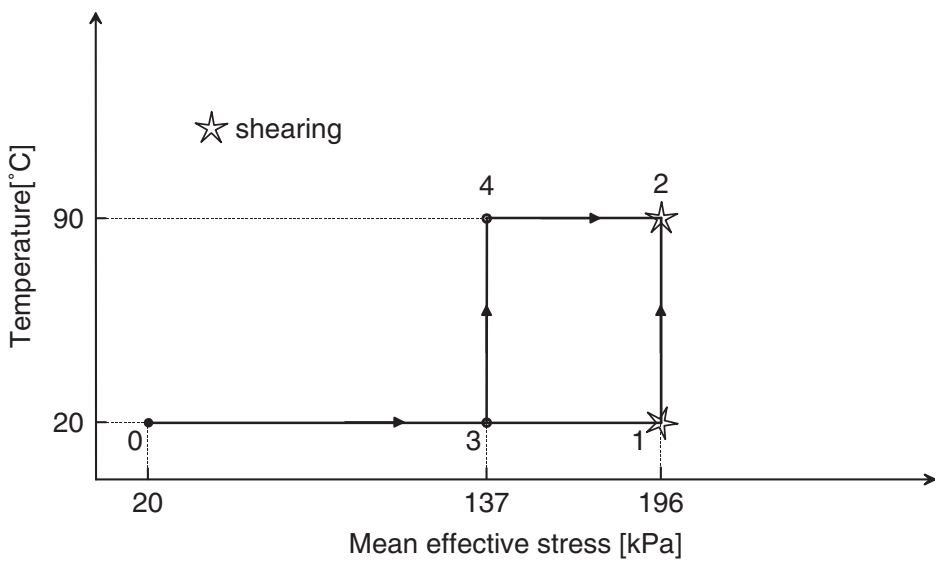

Figure 12. Experimental paths: stars mark points at which samples were sheared-MC clay.

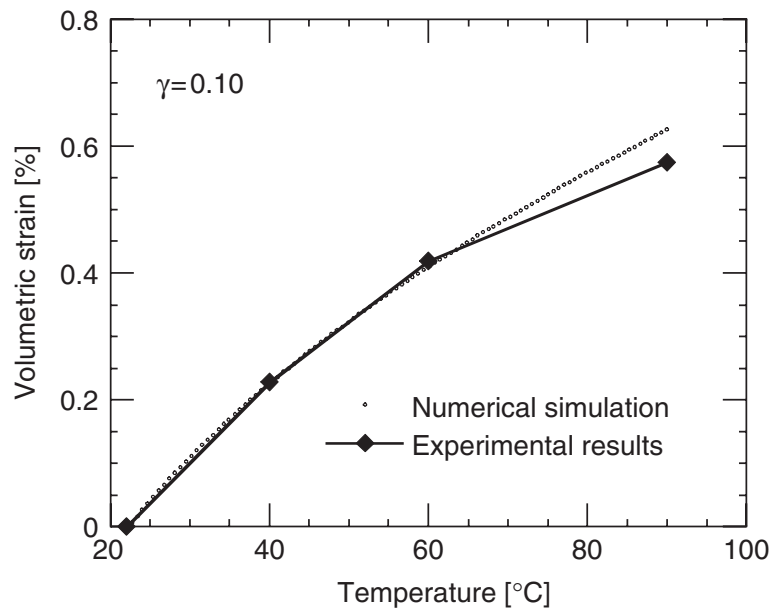

Figure 13. Calibration of the parameter $\gamma$ on drained heating test under oedometric conditions-initially normally consolidated MC clay.

- The predicted axial strains are only qualitatively representative. Even if the model is able to produce almost the same axial strain and pore water pressure for the first cycles, later shear cycles of the heated sample showed higher strains for numbers of cycles similar to those in the experiments.

- The pore water pressures are quantitatively well evaluated.

\subsection{Simulation of the behaviour of MC clay}

The simulations carried out are based on experimental results obtained from reconstituted samples from clay slurry made by mixing MC clay and water [30,31]. The properties of the MC clay are 

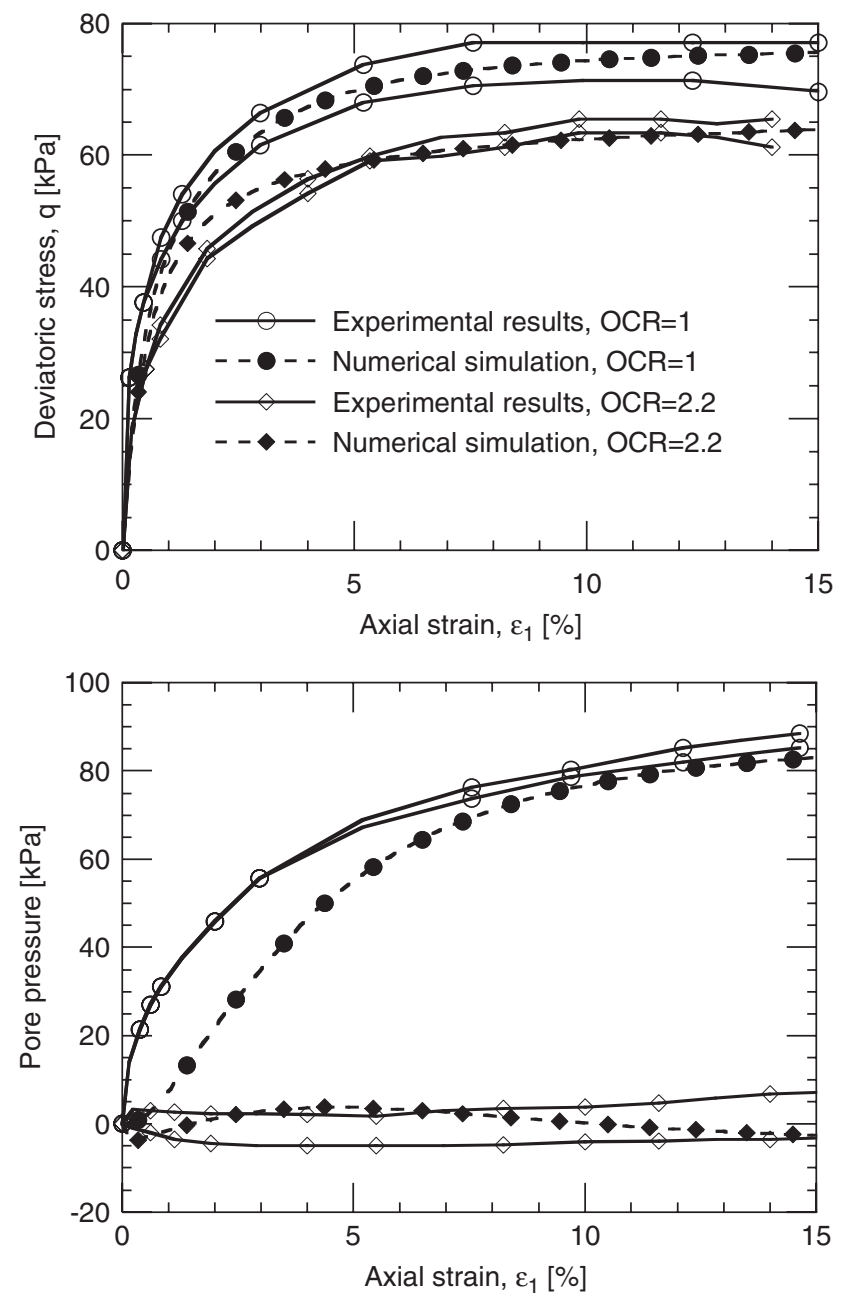

Figure 14. Comparison between numerical back-predictions and experimental results: undrained shear tests at room temperature in $\mathrm{NC}$ and $\mathrm{OC}(\mathrm{OCR}=2.2)$ states-MC clay.

given in Table I. The results were obtained for the paths given in Figure 12. Path $1(0 \rightarrow 3 \rightarrow 1)$ represents a conventional undrained triaxial test at ambient temperature: drained consolidation from 20 to $196 \mathrm{kPa}$ at $20^{\circ} \mathrm{C}$ ( $\mathrm{NC}$ case or unloading for $\mathrm{OCR}=2.2$ ), followed by shearing under undrained conditions. Path $2(0 \rightarrow 1 \rightarrow 2)$ starts with identical consolidation as for Path 1 , followed by heating to $90^{\circ} \mathrm{C}$ under drained conditions before shearing. Another path (Path 3) was tested but is not shown in Figure 12; it consisted of thermal loading (heating) under oedometric conditions. Experimental tests for Path 1 were carried out twice.

4.2.1. Calibration of model parameters and back-predictions. The material parameters of the $\mathrm{MC}$ clay were determined using four experimental tests: two triaxial shear tests in NC and OC 

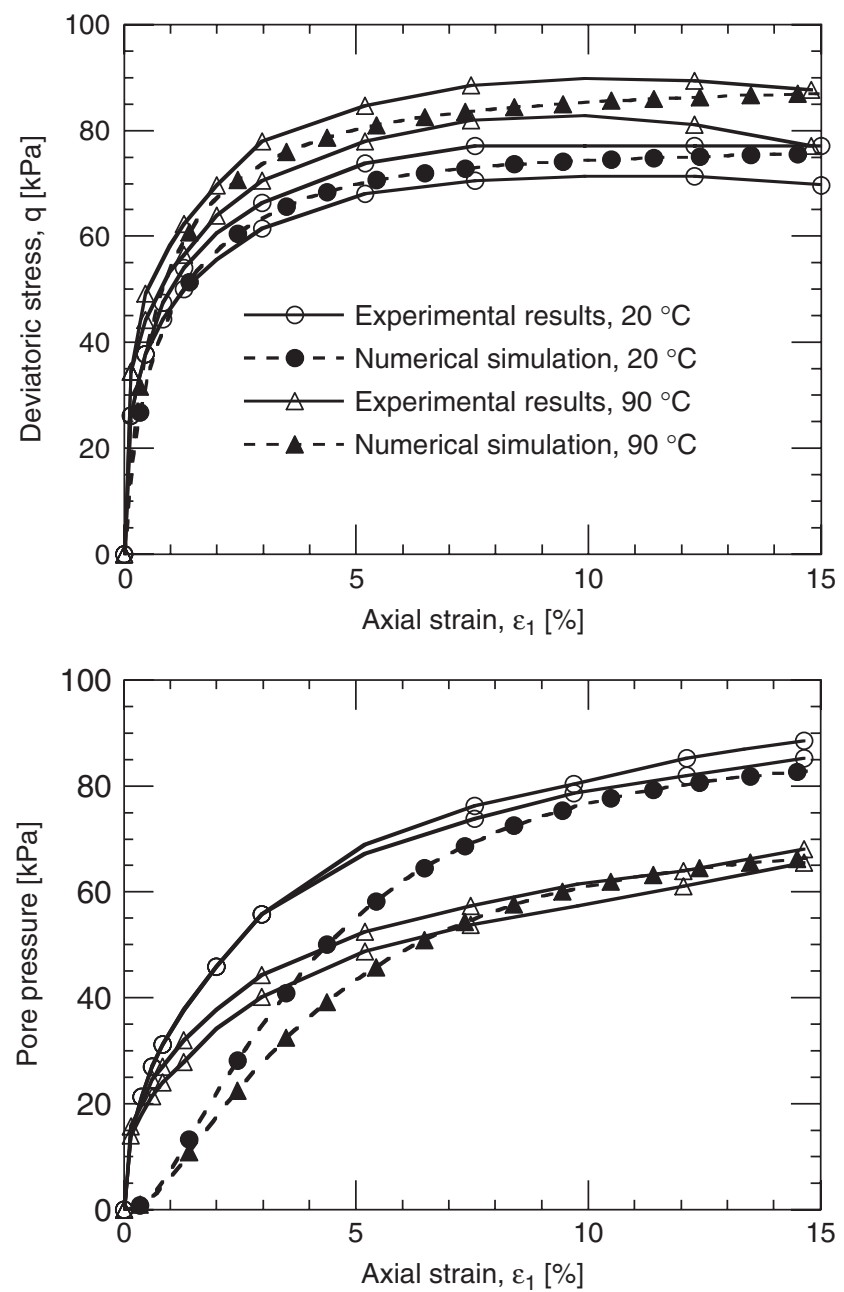

Figure 15. Comparison between numerical back-predictions and experimental results: undrained shear tests at different temperatures- $\mathrm{MC}$ clay.

$(\mathrm{OCR}=2.2)$ states at room temperature $\left(20^{\circ} \mathrm{C}\right.$, Path 1 for $\left.\mathrm{NC}\right)$, one triaxial test at high temperature $\left(90^{\circ} \mathrm{C}\right.$, Path 2) and one thermal loading (Path 3). The determination of the model parameters is similar to the procedure presented above for Kaolin clay and, therefore, will not be repeated here. Figure 13 shows the calibration of the thermal parameter $\gamma$ (Equation (9)) from the test on Path 3. On this drained oedometric path, the induced thermal strains in the initially NC sample are considered as purely thermo-plastic. The value of the volumetric thermal expansion coefficient $\beta_{\mathrm{s} 0}^{\prime}$ was taken from Kuntiwattanakul [30]. The model parameters are summarized in Table II. Back-predictions of the experimental results are shown in Figure 14 (triaxial shear tests in NC and $\mathrm{OC}$ states at room temperature, $20^{\circ} \mathrm{C}$, Path 1 ) and in Figure 15 (triaxial shear test in NC conditions at ambient and high temperatures, Paths 1 and 2). One can easily notice the good quality of the back-predictions both at ambient and high temperatures. 

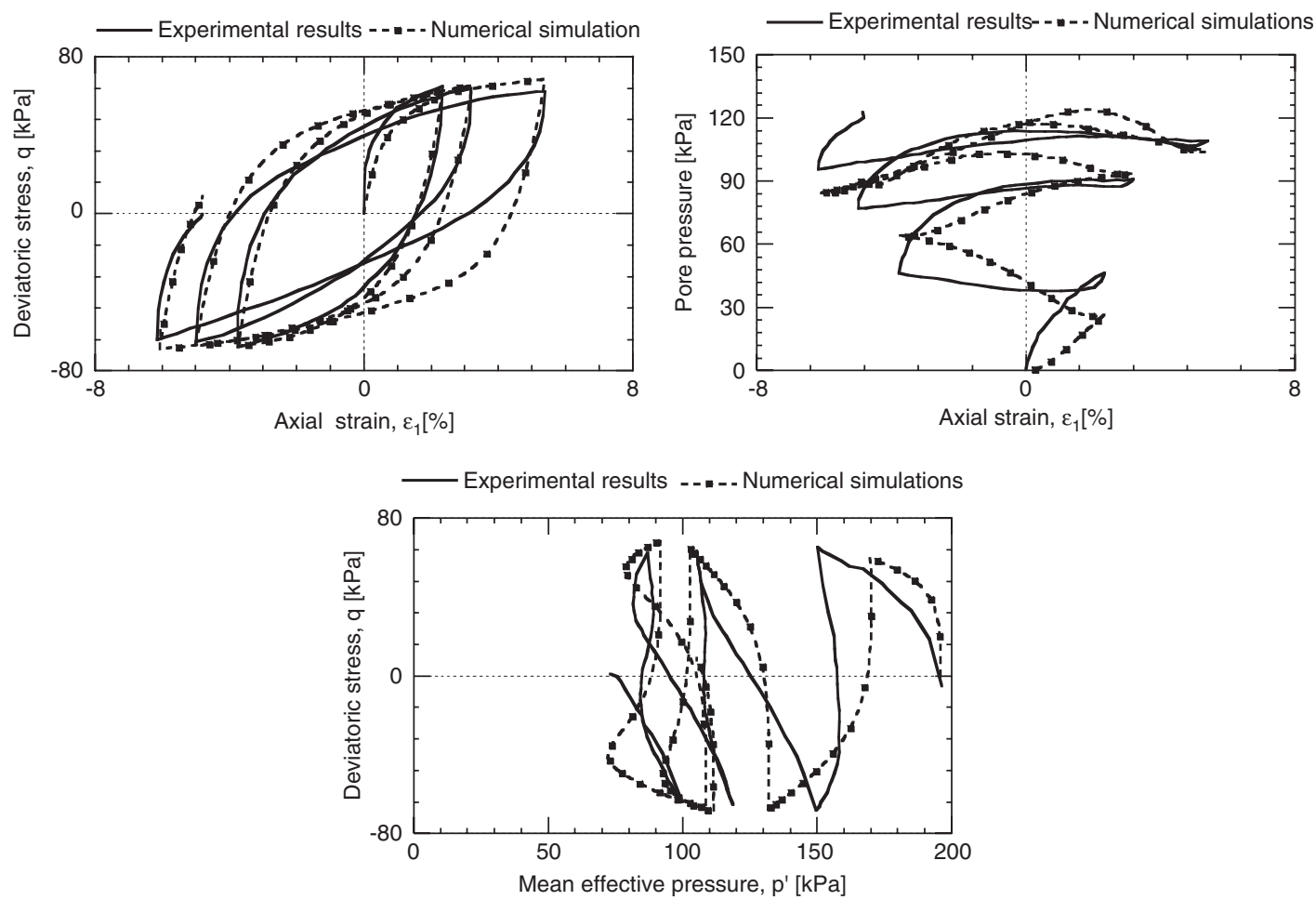

Figure 16. Numerical predictions and experimental results of cyclic undrained shear tests at $22^{\circ} \mathrm{C}-\mathrm{MC}$ clay.

4.2.2. Numerical modelling of the cyclic behaviour. Two specimens were consolidated at a pressure of $196 \mathrm{kPa}$ at room temperature. Then, one of them was cyclically sheared under undrained conditions at room temperature $\left(22^{\circ} \mathrm{C}\right)$ while the other was heated to $90^{\circ} \mathrm{C}$ under drained conditions and after that was cyclically sheared under undrained conditions at this temperature. The same deviatoric stress of $65 \mathrm{kPa}$ was applied in both experimental cases (stress-driven test). The numerical simulations were made under strain-driven conditions.

Comparisons between tests on the unheated (Figure 16) and the heated (Figure 17) samples show smaller strain induced by the cyclic shearing in the heated case and significantly smaller induced pore water pressure. These results mean that a larger increase in pore water pressure for the unheated sample results in smaller values of mean effective pressure.

Comparisons between experimental results and numerical predictions show very good agreement in the deviatoric stress-axial strain plane for both testing temperatures $\left(20\right.$ and $\left.90^{\circ} \mathrm{C}\right)$. The generated pore water pressure was slightly different from the experimental results, inducing a difference in the mean effective pressure-deviatoric stress plane. Small differences in the value of the maximal deviatoric stress can be attributed to the strain-driven simulations, contrary to the experimental test conditions (stress driven).

Generally, the model predictions are quite satisfactory and clearly show the capacities of the constitutive model for the simulation of the induced heat effect on cyclic mobility for different initial overconsolidation ratios. 

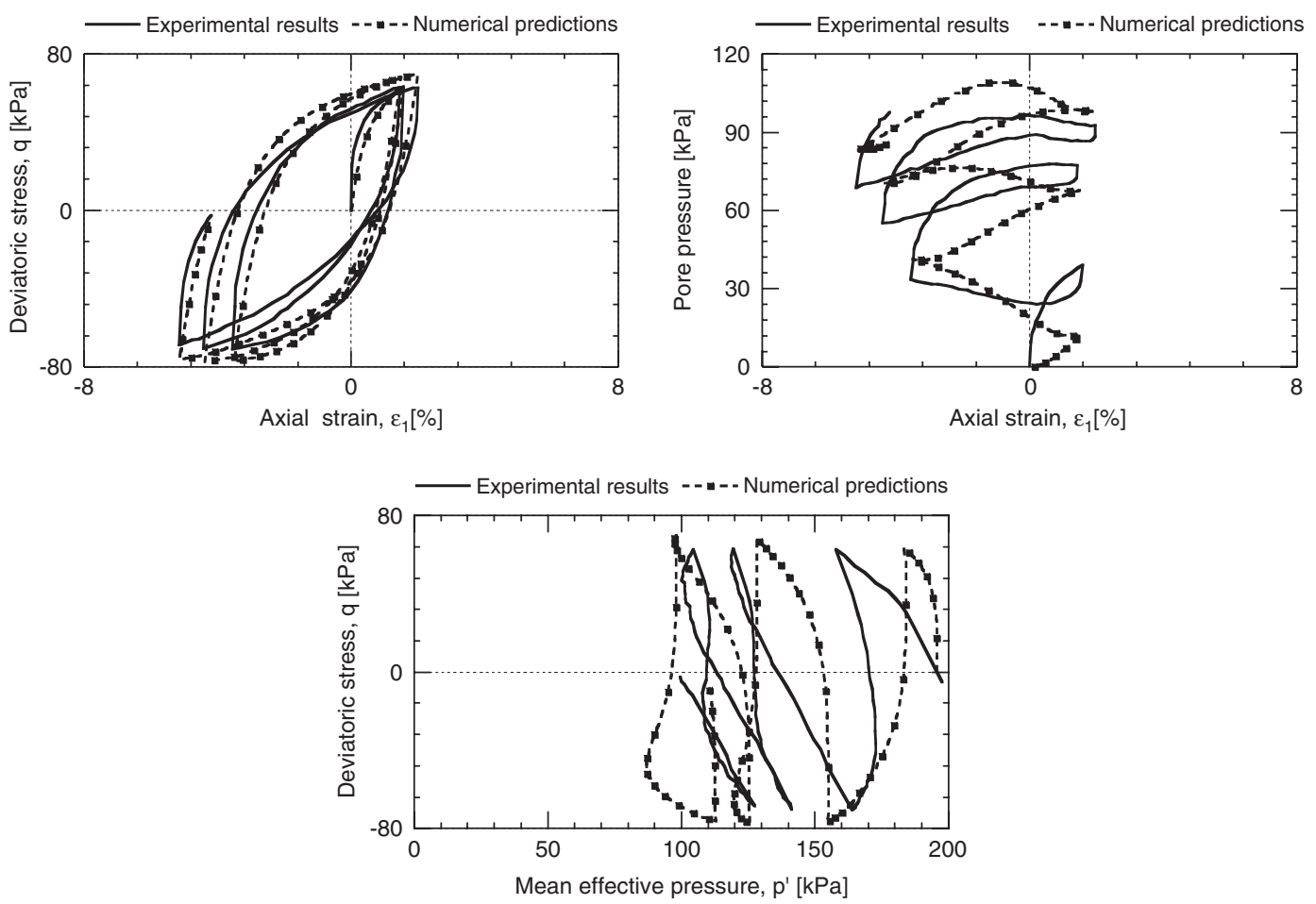

Figure 17. Numerical predictions and experimental results of cyclic undrained shear tests at $90^{\circ} \mathrm{C}-\mathrm{MC}$ clay.

\section{CONCLUSIONS}

As the range of potential problems in geomechanics with non-isothermal conditions becomes increasingly wider, it is important to understand and to improve the modelling of such behaviour. This paper addresses the constitutive modelling of cyclic mechanical behaviour at different temperatures.

An original thermo-mechanical framework is presented. It extends an existing multi-mechanism isothermal model to thermo-elasticity and thermal hardening. It includes the numerical simulations of the undrained paths using Biot's equations. After the model calibration, and in order to highlight the capabilities of the constitutive model in predicting the cyclic behaviour of heated soils, numerical simulations of cyclic shear triaxial tests, performed in undrained conditions on Kaolin clay and $\mathrm{MC}$ clay, after drained heating to $90^{\circ} \mathrm{C}$ are compared with the experimental results.

The proposed constitutive model showed good ability to predict the essentials of the cyclic behaviour at different temperatures. The model correctly captures isotropic thermal hardening and introduces it in deviatoric mechanisms, which enabled the capture of a difference in cyclic stress-strain behaviour at different temperatures. This allows the replication under non-isothermal conditions of the cyclic mobility phenomena for different initial overconsolidation ratios. 
The presented cyclic thermo-plastic model employed within general fully coupled (solid-fluid) thermo-hydro-mechanical finite element formulations is a powerful tool for solving boundary value problems under non-isothermal conditions including liquefaction and cyclic mobility.

\section{APPENDIX A: DETERMINATION OF THE MODEL PARAMETERS FOR THE KAOLIN CLAY}

To determine the elastic model parameters, the results at small strains (elastic domain) of two triaxial tests carried out at two different confining pressures and ambient temperature were used. The elastic shear parameter, $G_{\text {ref }}$, was identified by plotting the deviatoric stress $\left(\sigma_{1}-\sigma_{3}\right)$ as a function of the deviatoric strain, $2\left(\varepsilon_{1}-\varepsilon_{3}\right)$. The isotropic compression test at ambient temperature was used to obtain the bulk modulus, $K_{\text {ref }}$, which corresponds to the slope of the plot relating mean effective pressure versus volumetric strain. The non-linear exponent, $n$, was determined by combining the values of the parameter $G_{\text {ref }}$ obtained at two different confining pressures. Experimental results of the evolution of the bulk and shear moduli are compared in Figure A1 to the numerical back-predictions.

Concerning the plastic parameters, the slope of the critical state line, $M$, at room temperature, was determined from the results of two triaxial tests at ambient temperature. The critical state concept suggests that the strength of a soil at large strain, when the condition $\partial q / \partial \varepsilon_{\mathrm{s}}=\partial \varepsilon_{\mathrm{v}} / \partial \varepsilon_{\mathrm{s}}=0$ is satisfied, depends mainly on its mineralogy and not on how it was formed. Thus, the parameter $M$ is given by

$$
M=\frac{q_{\mathrm{c}}}{p_{\mathrm{c}}^{\prime}}=\frac{6 \sin \phi}{3-\sin \phi}
$$
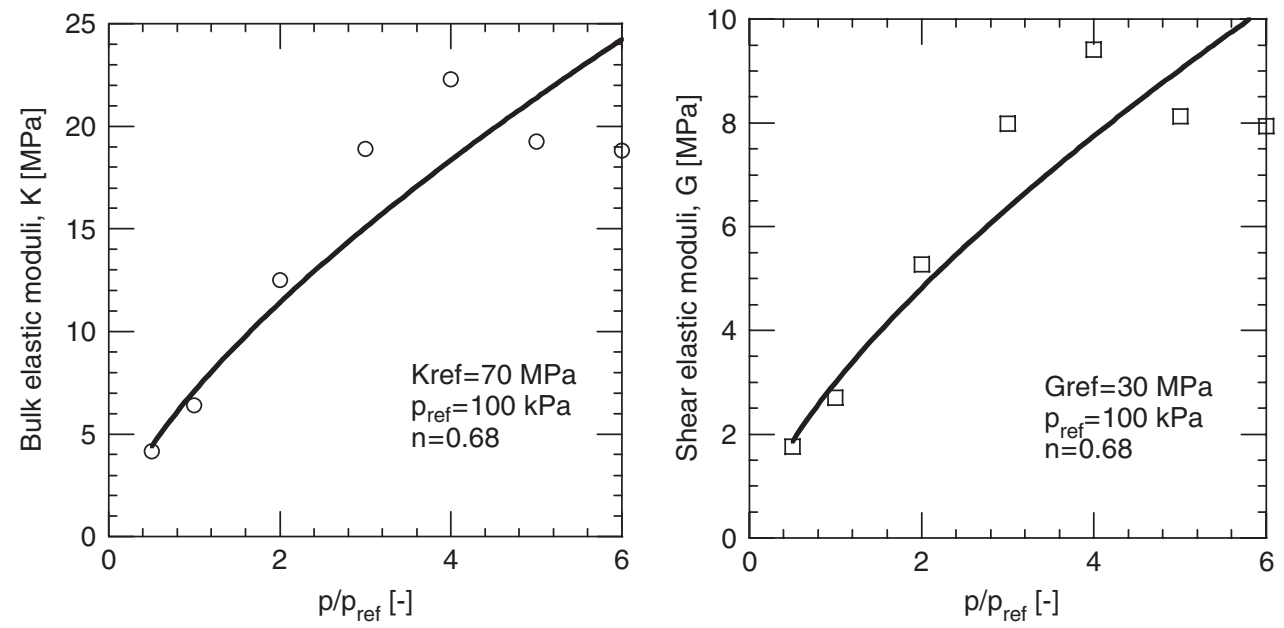

Figure A1. Evolution of the bulk and shear elastic moduli with cell pressure; experimental results (points) and numerical back-predictions (lines). 


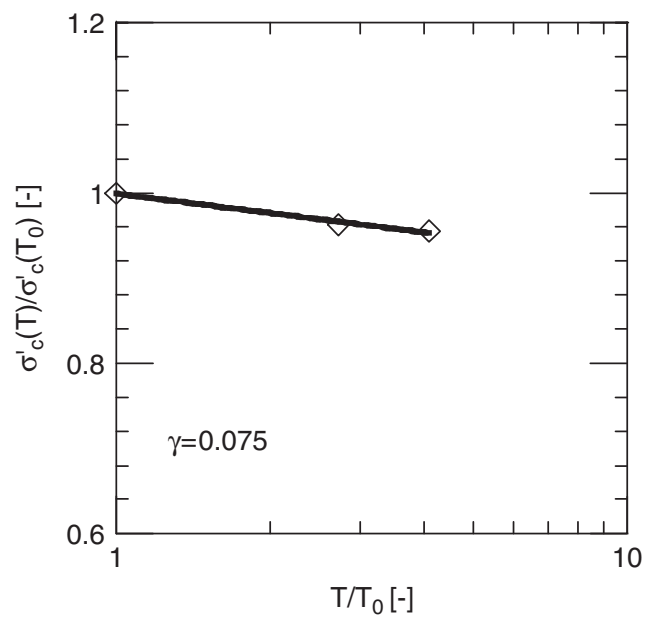

Figure A2. Determination of the parameter $\gamma$ : comparison of experimental results (points) and the numerical back-prediction (line).

where $q_{\mathrm{c}}$ and $p_{\mathrm{c}}^{\prime}$ are the deviatoric stress and the mean effective pressure, respectively, at the critical state. Therefore, Equation (A1) has been used to compute corresponding values of friction angle, $\phi$. The plastic compressibility modulus, $\beta$, was determined from the consolidation curve at ambient temperature using the following equation:

$$
\frac{1}{\beta}=\frac{\lambda-\kappa}{1+e_{0}}
$$

where $\lambda$ and $\kappa$ are the plastic and the elastic (swelling) slopes of the normal consolidation line, in the $\ln p^{\prime}-e$ plane, respectively. $e$ and $e_{0}$ are the void ratio and the initial void ratio, respectively. The initial critical state pressure, $p_{\mathrm{c} 0}^{\prime}$, defines the initial stress state of the material. It was evaluated from the equation of the critical state line:

$$
v=\Gamma-\lambda \ln p^{\prime}
$$

where $v$ is the specific void ratio, $v=1+e_{0}$, and $\Gamma$ its initial value. The internal parameter $b$ determines the curvature of the deviatoric yield surface between Mohr-Coulomb for $b=0$ and Cam-Clay for $b=1$. The determination of the parameter $b$ was based on numerical calibration using two triaxial tests at different confining pressures at ambient temperature. The parameter $d$ has been defined by Equation (13) and been determined accordingly by using the critical state and preconsolidation pressure ratio.

Concerning the cyclic parameters, as may be seen from Equation (25), the parameter $r_{k}$ represents a degree of mobilization for a given mechanism. If $\alpha_{k}^{\Xi}=1$ is assumed in primary loading, the degree of mobilization is a hyperbole with a slope at the origin of $1 / a_{\mathrm{m}}$ [22]. Thus, the parameter $a_{\mathrm{m}}$ was identified by plotting the normalized deviatoric stress versus plastic shear strain. The parameter $a_{\mathrm{c}}$ corresponds to cyclic loading and was obtained by the same procedure. Moreover, both parameters can also be identified by numerical calibration. In addition to preconsolidation pressure at reference temperature, $\sigma_{\mathrm{c} 0}^{\prime}$, two isotropic consolidation tests at high temperatures $\left(60\right.$ and $\left.90^{\circ} \mathrm{C}\right)$ were used 
to obtain the parameter $\gamma$, which corresponds to the slope of the normalized plot $\sigma_{\mathrm{c}}^{\prime} / \sigma_{\mathrm{c} 0}^{\prime}$ versus $\log \left(T / T_{0}\right)$ (Figure A2).

The hysteretic and mobilized domain parameters should satisfy the following condition: $r_{\mathrm{el}} \leqslant r_{\text {hys }} \leqslant r_{\text {mob. }}$. In general, the elastic domain should be fixed over the range $\{0.001-0.01\}$ and for the Kaolin clay the value was fixed at 0.001 . The hysteretic domain, $r_{\text {hys }}$, and the mobilized domain, $r_{\mathrm{mob}}$, were determined by numerical calibration.

For the thermal parameters, the initial thermal expansion coefficient of the solid skeleton, $\beta_{\mathrm{s} 0}^{\prime}$, was assumed to be $\beta_{\mathrm{s} 0}^{\prime}=3 \times 10^{-5 \circ} \mathrm{C}^{-1}$ as suggested by Campanella and Mitchell [32]. Moreover, the Handbook of Chemistry and Physics (2000) [33] gives a range from $1.5 \times 10^{-5 \circ} \mathrm{C}^{-1}$ to $5.2 \times 10^{-5 \circ} \mathrm{C}^{-1}$ for minerals such as $\mathrm{SiO}_{2}, \mathrm{Al}_{2} \mathrm{O}_{3}$, quartz, slate and brick fire clay; thus, an average value for clays would be about $3 \times 10^{-5 \circ} \mathrm{C}^{-1}$. The thermal expansion coefficient of water is assumed to be a constant over the temperature range considered in this study, and equal to $\beta_{\mathrm{f}}^{\prime}=4 \times 10^{-4 \circ} \mathrm{C}^{-1}$.

\section{ACKNOWLEDGEMENTS}

The authors wish to express their thanks to Profs H. Modaressi (BRGM) and D. Aubry (Ecole Centrale Paris) for providing the original driver of the Hujeux constitutive model.

\section{REFERENCES}

1. Laloui L, Moreni M, Vulliet L. Comportement d'un pieu bi-fonction, fondation et échangeur de chaleur. Canadian Geotechnical Journal 2003; 40(2):388-402.

2. Laloui L, Nuth M, Vulliet L. Experimental, numerical investigations of the behaviour of a heat exchanger pile. International Journal for Numerical and Analytical Methods in Geomechanics 2006; 30(8):763-781.

3. Cekerevac C, Laloui L. Experimental study of the thermal effects on the mechanical behaviour of a clay. International Journal for Numerical and Analytical Methods in Geomechanics 2004; 28(3):209-228.

4. Cekerevac C, Laloui L. Non-isothermal experimental analysis of the cyclic behaviour of a Kaolin clay. Géotechnique 2007, submitted.

5. Khalili N, Habte MA, Valliappan S. A bounding surface plasticity model for cyclic loading of granular soils. International Journal for Numerical Methods in Engineering 2005; 63(14):1939-1960.

6. Castro G. Liquefaction and cyclic mobility of sands. Journal of Geotechnical Engineering (ASCE) 1975; 101(GT6):551-569.

7. Pastor M, Zienkiewicz OC, Chan AHC. Generalized plasticity and the modelling of soil behaviour. International Journal for Numerical and Analytical Methods in Geomechanics 1990; 14(3):151-190.

8. Zienkiewicz OC, Chan AHC, Pastor M, Schrefler BA, Shiomi T. Computational Geomechanics: With Special Reference to Earthquake Engineering. Wiley: New York, 1999.

9. Elgamal A, Yang Z, Parra E, Ragheb A. Modeling of cyclic mobility in saturated cohesionless soils. International Journal of Plasticity 2003; 19:883-905.

10. Hueckel T, Borsetto M. Thermoplasticity of saturated soils and shales: constitutive equations. Journal of Geotechnical Engineering 1990; 116(2):1765-1777.

11. Cui YJ, Sultan N, Delage P. A thermomechanical model for saturated clays. Canadian Geotechnical Journal 2000; 37:607-620.

12. Laloui L, Cekerevac C. Thermo-plasticity of clays: an isotropic yield mechanism. Computers and Geotechnics 2003; 30(8):649-660.

13. Laloui L, Cekerevac C, François B. Constitutive modelling of the thermo-plastic behaviour of soils. Revue Européenne de Génie Civil 2005; 9(5-6):635-650.

14. Modaressi H, Laloui L. Thermo-viscoplastic model for clays. International Journal for Numerical and Analytical Methods in Geomechanics 1997; 21:313-335.

15. Laloui L. Thermo-mechanical behaviour of soils. Revue Française de Génie Civil 2001; 5:809-843. 
16. Cekerevac C. Thermal effects on the mechanical behaviour of saturated soils: an experimental, constitutive and numerical approach. Ph.D. Dissertation No. 2828, EPF Lausanne, 2003; 233.

17. Prager W. Non-isothermal plastic deformation. Koninke-Nederland Akademie Van Wetenschappen Te Amsterdam 1958; 8(61/3):176-182.

18. Laloui L. Modélisation du comportement thermo-hydro-mécanique des milieux poreux anélastiques. Doctoral Thesis, Ecole Centrale Paris, 1993.

19. Koiter J. General theorems for elastoplastic solids. Progress in Solid Mechanics, vol. 1. North-Holland: Amsterdam, $1960 ; 165-221$.

20. Mandel J. Généralisation de la théorie de la plasticité de W.T. Koiter. International Journal of Solids and Structures 1965; 1:273-295.

21. Aubry D, Hujeux JC, Lassoudiere F, Meimon Y. A double memory model with multiple mechanisms for cyclic soil behaviour. International Symposium on Numerical Models in Geomechanics, Zürich, 1982.

22. Hujeux JC. Une loi de Comportement Pour le Chargement Cyclique des Sols. Génie parasismique. Editions ENPC: Paris, 1985; 287-353.

23. Mroz Z, Norris VA, Zienkiewicz OC. An anisotropic model for soils and its application to cyclic loading. International Journal of Numerical Methods 1978; 2(3).

24. Roscoe KH, Burland IB. On the generalised stress-strain behaviour of wet clay. Engineering Plasticity. Cambridge University Press: Cambridge, 1968; 535-609.

25. Biot MA. Theory of propagation of elastic waves in fluid-saturated porous solid. Journal of the Acoustical Society of America 1956; 28:168-178.

26. Cekerevac C, Laloui L, Vulliet L. A novel triaxial apparatus for thermo-mechanical testing of soils. Geotechnical Testing Journal 2005; 28(2):161-170.

27. Lopez-Quezol S, Blazquez R. Liquefaction and cyclic mobility model for saturated granular media. International Journal for Numerical and Analytical Methods in Geomechanics 2006; 30:413-439.

28. Alarcon-Guzman A, Leonards GA, Chameau JL. Undrained monotonic and cyclic strength of sands. Journal of Geotechnical Engineering 1988; 114(10):1089-1109.

29. Biarez J, Hicher PY. Elementary Mechanics of Soil Behaviour: Saturated Remoulded Soils. Balkema: Rotterdam, 1994.

30. Kuntiwattanakul P. Effect of high temperature on mechanical behaviour of clays. Doctoral Thesis, University of Tokyo, 1991.

31. Kuntiwattanakul P, Towhata I, Ohishi K, Seko I. Temperature effects on undrained shear characteristics of clay. Soils and Foundations 1995; 35(1):147-162.

32. Campanella RG, Mitchell JK. Influence of temperature variations on soil behavior. Journal of the Soil Mechanics and Foundation Division, ASCE, 1968; 94(SM3):709-734.

33. Lide DR (ed.). Handbook of Chemistry and Physics (81st edn), 2000. 